\title{
Operative Management of Intra-Articular Fractures of Distal Humerus in Adult
}

\author{
Salman Adil, S Abdur Rub Abidi, Shaikh Naeemul Haque, Haris Hirani, Aslam Siddiqui, \\ Shah Kamal Hashmi, Shahtaj Shah
}

\begin{abstract}
OBJECTIVE: To assess the results of operative treatment of intra-articular fractures of distal humerus in adult.

METHODOLOGY: This descriptive, non-randomized, uncontrolled study using convenience sampling technique was carried out at Fatima Hospital Baqai Medical University and Jinnah Medical College Hospital's Orthopedic Departments between March 2012 and Feb 2016.

The study was based on a total of 20 patients with an AO Type C; Closed and Open-Gustilo Type-I fractures of distal humerus. The age range of participants was between 18 to 52 years (inclusive) and belonged to both sexes. All patients were operated under general anaesthesia. Trans-olecranon and posterior Campbell's approaches were used. Fractures were secured through reconstruction or dynamic compression plates and inter-fragmentary screws. Posterior splint was applied post-operatively.

SPSS version 20 was used to analyze the data received after following up from the patients under study.

RESULTS: Evaluations of the patients were done as per the guidelines of Mayo Elbow Performance (MEP) Score. The results were excellent in $10 \%$, good in $60 \%$, fair in $25 \%$; and poor in $5 \%$ cases.

CONCLUSION: For adults, stable internal fixation of intra-articular fractures of distal humerus is termed as gold standard. It requires adequate surgical exposure, careful operative planning, anatomical reduction of articular fragments and early active rehabilitation.
\end{abstract}

KEYWORDS: Intra-articular fractures, Distal Humerus.

This article may be cited as: Adil S, Abidi SAR, Haque SN, Hirani H, Siddiqui A, Hashmi SK, et al. Operative Management of Intra-Articular Fractures of Distal Humerus in Adult. J Liaquat Uni Med Health Sci. 2018;17(04):245-8. doi: 10.22442/jlumhs.181740586

\section{INTRODUCTION}

A general basis for an Intra-articular fracture is indirect trauma in which olecranon impact against the articular surface of the distal humerus resulting it to split ${ }^{1,2}$ and the fracture is usually comminuted ${ }^{3}$. As recommended and most preferred treatment of intra-articular, inter condylar fractures of distal humerus is open reduction and internal fixation ${ }^{4}$. The ultimate outcome is depended upon stable anatomical reconstruction of the joint surface and early range of motion exercise of elbow joint.

The ultimate goals of the treatment of these fractures are as follows:

a) A stable and mobile articulation;

b) Union between metaphyseal and epiphyseal fragments;

c) Restoration of metaphyseal bone stock and

d) Healing of Soft tissue

In considering exposure of the distal humerus one should be aware that "The front door of the Elbow is at the back" ${ }^{\prime 2}$. The usually recommended surgical approaches to these fractures are posterior
Campbell's approach and Trans-olecranon approach. The underlying objectives of Osteosynthesis (method of fixation) of fragments of distal humerus are:

Reduction and Fixation of the Condyles ${ }^{6}$ : Using K-wires; Malleolar or Cancellous AO Screws of 6.5 $\mathrm{mm} ; 4 \mathrm{~mm}$ Cannulated screws.

Reduction and Fixation of the medial and Lateral Epicondylar ridge if it is fractured: Using K-wire and Lag screws.

Reduction and Fixation of the condyles to humeral metaphysis: Using screws, threaded pins or plates (reconstruction or dynamic compression plate).

Soft tissue healing.

Generally lateral column is fixed with $3.5 \mathrm{~mm}$ reconstruction plate on posterior aspect of lateral column and $3.5 \mathrm{~mm}$ reconstruction plate on medial aspect of medial column. If necessary, Lag screws and dynamic compression plate can be applied.

The open reduction and internal fixation of an intra-articular distal humerus fractures carries the high risk of infection ${ }^{7}$, post op neuritis $(15-28 \%)^{7}$, non-union $(1-11 \%)$, hard ware loosening, Heterotopic ossification (3-30\%) and elbow stiffness. 


\section{METHODOLOGY}

This research being hospital based, using convenience sampling technique, in an uncontrolled environment with non-probability elements was undertaken at Fatima Hospital Baqai Medical University and Jinnah Medical College Hospital's Orthopedic Department between March 2012 and Feb 2016. We included Twenty (20) patients with AO Type C; Closed and Open-Gustilo Type-I fractures of distal humerus of either sex, between 18 to 52 years of age. Samples excluded individuals with were severe osteoporosis, previous fractures around elbow, pathological fractures, another fracture of ipsilateral limb and patient became unfit for surgery.

It was noted that majority of the patients were admitted in the hospital through Accident and Emergency Department. Once admitted, a thorough background check and clinical examination were undertaken. Roentgenograms of distal humerus with elbow were taken. The patients were operated under general anaesthesia. Tourniquet was applied. Posterior Campbell's approaches and Trans-olecranon were used. Thorough debridement was performed in case of Gustilo Type-I fracture. Fractures were stabilized and fixed by K-wire, Malleolar screws, Cannulated screws, Dynamic compression plates and reconstruction plates depending upon the types of fractures. After the operation was done successfully Back slab was applied for a week. In order to start active range of movement exercises, it was important for the wound to heal and swelling to subside. A triangular sling was kept for 6-8 weeks and supervised physiotherapy continued for 12-14 weeks. Evaluations of the patients were done as per the guidelines of Mayo Elbow Performance (MEP) Score. The MEP Score is an elbow centric score that assess the pain, mobility, stability and function of the elbow. Statistical analysis was performed by SPSS.

\section{RESULTS}

Out of twenty (20) patients, eight (8) were females $(40 \%)$ and twelve (12) were males $(60 \%)$. Mean age was $32 \mathrm{SD}+10-5$ There were Six (6) patients $(30 \%)$ with AO type C I fractures; eight (8) patients $(40 \%)$ with type C 2 and six (6) patients (30\%) with type C 3 fractures. Two (2) patients $(10 \%)$ had Gustilo type I (all males, one with gunshot and one after road traffic accident). Posterior Campbell's approach was used in fourteen (14) patients (70\%) and Trans-olecranon approach was done in Six (6) patients (30\%).

In Six (6) type C I patients (30\%) fractures Osteosynthesis were achieved by Inter-condylar Malleolar screws, one-third tubular plate and reconstruction plate.
Eight (8) Type C 2 patients (40\%) were fixed with Inter -condylar Malleolar screw and later on condyles were assembled with metaphysis with reconstruction plate. For metaphyseal comminution inter-fragmentary screws were also used.

Five (5) Type C 3 fractures were fixed with inter-condylar Malleolar screw and reconstruction plates. In one Type C 3 plus Gustilo type I fracture minimal Osteosynthesis was achieved by $\mathrm{K}$-wires and inter-fragmentary screws only.

The follow up period ranged from 6 to 12 months SD $10.1 \pm 3$ weeks. Radiological union was seen at 16 to 28 weeks. The average duration of radiological union was $16+04$ weeks in 12 cases $(60 \%)$ and $18+04$ weeks in 4 patients $(20 \%)$ and $20 \pm 06$ in 4 patients $(20 \%)$.

Two (2) patients (10\%) had mean arc of flexion of 110 degrees $\mathrm{SD} \pm 10$ which were termed as excellent. Twelve (12) patients (60\%) had mean arc of flexion of 80 degrees SD+10 which were related as good. Five (5) patients $(25 \%)$ had mean arc of flexion of less than 50 degrees $\mathrm{SD} \pm 6$ which were related as fair and one (1) patients $(5 \%)$ had mean arc of flexion 20 degrees $\mathrm{SD} \pm 0$; termed as poor.

\begin{tabular}{|l|c|c|}
\hline \multicolumn{3}{|c|}{ Mayo Elbow Score } \\
\hline \multicolumn{1}{|c|}{ Group } & No of Cases & MEP Score \\
\hline Excellent & 2 & $10 \%$ \\
\hline Good & 12 & $60 \%$ \\
\hline Fair & 5 & $25 \%$ \\
\hline Poor & 1 & $5 \%$ \\
\hline
\end{tabular}

Twelve (12) out of thirteen (15) patients with age less than 35 years had excellent and good result and two (2) out of five (5) patients with age greater than 35 had good results. $P$ value less than 0.05 is significant in young age group for better function outcome. According to criteria of Mayo Elbow Performance Score the results was excellent $/$ good in $70 \%$ cases. Early post-operative complication developed in two (2) patients (10\%): including infection (in 1) and iatrogenic neuritis (in 1).

\section{DISSCUSION}

Distal humerus fractures are relatively uncommon orthopaedic injuries, representing less than $7 \%$ of adult fractures and approximately $30 \%$ of fractures around the elbow ${ }^{8}$. Treatment of intra-articular distal humerus fractures is a challenging task. These fractures usually compounded by significant comminution and multiple intra articular lines ${ }^{9}$. These fractures due to intra-articular involvement and poor control of fracture fragments with closed treatment are 
typically treated by operatively. The decision of operative treatment is based on many factors, including fracture types, intra-articular involvement, fragments displacement, bone quality, joint stability and soft tissue condition and coverage ${ }^{10}$.

The aims of treatment in these fractures are restoring painless and functional elbow which is achieved by anatomical reconstruction and stable fixation ${ }^{11}$. Pre-operatively patients must understand outcome expectation and importance of rehabilitation. This post -op rehabilitation allows early range of movement and decrease elbow stiffness ${ }^{10}$.

In our study we presented the result of consistent controlled surgical treatment using current orthopedic techniques, implants and controlled post-operative mobilization. We used two (2) approaches posterior Campbell's $^{12}$ and Trans-olecranon approaches ${ }^{13}$. Campbell's approach is safe for ORIF of the difficult fractures and functional and cosmetic results are satisfactory. Trans-olecranon approach provides excellent exposure of the articular surface without excessive soft tissue trauma.

In our study we treated twenty (20) patients with open reduction and internal fixation with Malleolar screws and plating. Out of 20 patients twelve (12) were males (60\%) and eight (8) were females (40\%), comparable to study by Shaik RB $2017^{14}$.

All patients in our study achieved fractures union with mean MEP score excellent in $2(10 \%)$, good in 12 (60\%) patients. We achieved Good to Excellent result in $70 \%$ cases, comparable to Chouhan S $2018^{15}$. Our range of motion results are consistent with those of other studies Elhage R $2001^{16} 67 \%$, Caja VL $1994^{17}$ $70 \%$ for the repair of intra-articular distal humerus fractures. It is noteworthy that the clinical evaluation didn't always correlate with follow up radiograph.

\section{CONCLUSION}

It was found out that surgical intervention is required for Intra-articular fracture of distal humerus. In order to ensure effective result, it is highly contingent on vigilant pre-operative strategy, sufficient exposure, anatomical articular fragment reduction, stable fixation and early active rehabilitation. A satisfactory functional result could be achieved by following these steps.

Limitation of Study: The sample size was small.

\section{REFERENCES}

1. Watts A, Warwick D. Injuries of the elbow and forearm. In: Blom A, Warwick D, Whitehouse M, editors. Apley \& Solomon's System of orthopaedics and trauma. $10^{\text {th }}$ ed. Boca Raton, Florida. CRC Press. 2018: 773-797.
2. Wick SJ, Meyer PR. Fractures of the distal humerus in adults. J Orthop Clin North Am 1967; 50: 43-51.

3. Babst R. Humerus: Humerus, distal. In: M Wagner, R Frigg, editors. AO manual of fracture management: Internal fixators. Davos: AO Publishing. 2006; 331-336.

4. O'Driscol SW. The triceps-reflecting anconeus pedicle (TRP) approach for distal humerus fractures and nonunions. Orthop Clin North Am. 2000; 31: 91-101.

5. Perez EA. Fractures of the shoulder, arm, and forearm. In: Azar FM, Canale T, Beaty J, editors. Campbell's operative orthopaedics. 13th ed. Philadelphia: Elsevier. 2017; 2961-69.

6. Grant SD, Gorezyea JT, Pugh KJ. Open distal humerus fractures. Proc Annual Orthopaedic Trauma Association Meeting. Boston. 1996: 269.

7. Kinik $\mathrm{H}$, Atalar $\mathrm{H}$, Mergen $E$. Management of distal humerus fractures in adults. Arch Orthop Trauma Surg. 1999; 119 (7-8): 467-9.

8. Miller AN, Beingessner DM. Intra-articular distal humerus fractures. Orthop Clin north Am. 2013; 44(1): 35-45. doi: 10.1016/j.ocl.2012.08.010.

9. Virani SR, Sonone S, Dahapute AA, Panda I, Roy KD. Functional Results of Communited Intraarticular Distal Humerus Fractures Treated with Bicolumnar Plating. J Clin Diagn Res. 2017; 11(4): RC01 -RC03.

10. Yian E. Distal Humerus Fractures Treatment \& Management. [Internet]. Medscape. October 23, 2017; Available from: https://emedicine. medscape.com/article/1239515-treatment

11. Kiran GU, Shashidhara H, Manjunath J, Akshay MK, Muralidhar A. A prospective study of functional outcome in intraraticular lower end of humerus fracture treated with dual plating. Int $\mathrm{J}$ Orthop Sci. 2017; 3(3): 37-42.

12. Crenshaw AH Jr. Surgical techniques and approaches. In: Azar FM, Canale T, Beaty J, editors. Campbell's operative orthopaedics. 13th ed. Philadelphia: Elsevier. 2017; 113-117.

13. MacAusland WR. Ankylosis of the elbow: With report of four cases treated by arthroplasty. JAMA. 1915; 64: 312-318.

14. Shaik RB, Reddy PV, Naidu KA. Study of clinical outcome in intra articular distal humerus fractures treated with dual plating. Int J Res Med Sci. 2017; 5(6):2438-2441.

15. Chouhan S, Bhinde S, Shekhawat YS, Panwar N, Bajoria RS. A prospective study of functional outcome in intra articular distal humerus treated with dual plating. Int J Orthop Science. 2018; 4 (2):51-55. 
16. Elhage R, Maynou C, Jugnet PM, Mestdagh $H$. Long-term results of the surgical treatment of bicondylar fractures of distal humerus extremity in adults. Chir Main. 2001; 20(2):144-54.
17. Caja VL, Moroni A, Vendemia V, Sabato C, Zinghi G. Surgical treatment of bicondylar of the distal humerus. Injury. 1994; 25(7): 433-8.

AUTHOR AFFILIATION:

Dr. Salman Adil (Corresponding Author) Assistant Professor, Department of Orthopedics Baqai Medical University, Karachi, Sindh-Pakistan.

Email: defencedr@hotmail.com

Dr. S Abdur Rub Abidi

Consultant, Department of Orthopedics

JMCH, Karachi, Sindh-Pakistan.

Dr. Shaikh Naeemul Haque

Assistant Professor, Department of Orthopedics

Dow International Medical College

Karachi, Sindh-Pakistan.

Dr. Haris Hirani

House Officer, Department of Orthopedics

Baqai Medical University

Karachi, Sindh-Pakistan.

Dr. Aslam Siddiqui

Professor, Department of Orthopedics

Baqai Medical University

Karachi, Sindh-Pakistan.

Dr. Shah Kamal Hashmi

Assistant Professor, Department of Public Health

Dow International Medical College

Karachi, Sindh-Pakistan.

Dr. Shahtaj Shah

Student, Department of Surgery

$\mathrm{JMCH}$, Karachi, Sindh-Pakistan. 